\title{
The Study of Adsorption Ability of Natural Materials of the Tyumen Region
}

\author{
Lyudmila Pimneva', Alla Zagorskaya ${ }^{2^{*}}$ \\ 1 Department of General and Special Chemistry, Tyumen Indusrial University, Lunacharskogo St., Tyumen \\ 625001, Russia \\ 2 Department of Industrial Safety, Tyumen Indusrial University, Lunacharskogo St., Tyumen 625001, Russia \\ * Corresponding author's e-mail: 4examples@mail.ru
}

\begin{abstract}
The sorption of divalent copper, natural sorbents of kaolinite and montmorillonite clays and carbon sorbent was studied on model solutions under static conditions. Quantitative characteristics of sorption process of copper ions were obtained. The degree of extraction of copper ions from solution was investigated, depending on the concentration of the initial solution and the weight ratio of the sorbent and volume of treated solution. The magnitude of sorption increases along with the increase in the volume of copper sulfate solution with a concentration of $0.02 \mathrm{M}$ at a constant sample of sorbents. A higher carbon sorption capacity of the sorbent, in relation to ions of copper, was compared to kaolinite and montmorillonite clay. A higher sorption capacity of the carbon sorbent with respect to copper ions is established in the comparison with kaolinite and montmorillonite clay.
\end{abstract}

Keywords: natural sorbent; copper ions; adsorption isotherms, water supply system, drinking water quality

\section{INTRODUCTION}

The accumulation of metal ions in the components of the environment is a territorial problem of the Tyumen region [Bykova et al. 2014; Gayevaya et al. 2013; Skipin, et al. 2014]. One of the reasons for the intensive contamination by ions of heavy metals is the unsatisfactory ecological state of water bodies associated with the transit of pollution, i.e. large rivers that form in the upstream areas (Sverdlovsk, Kurgan, Omsk regions and the Republic of Kazakhstan) [Government of the Tyumen region, 2016]. The influence of industrial wastewater on water objects contributes to the stable dynamics of copper concentration growth in the waterways and reservoirs of the city of Tyumen, some of which are sources of drinking water supply. [Guzeeva, 2014; Government of the Tyumen region, 2016].

The conducted engineering and technical analysis revealed that the existing facilities for water treatment in the city of Tyumen do not allow to ensure the appropriate quality of drinking water, including copper ions. The main reasons are:
- high wear of the water intake (up to $68 \%$ ) and water treatment (up to $99 \%$ ) structures;

- obsolete technological schemes of purification [Tyumen City Duma, 2009].

All these factors lead to secondary contamination of potable water in the centralized water supply systems, which provide for the drinking needs of more than 700,000 people. [Turnaeva, etc. 2015].

The accumulation of copper ions and influence on the population of the Tyumen region is indirectly confirmed by the morbidity statistics. Over the past three years, the deaths resulting from endocrine system diseases, eating disorders and metabolic disorders increased by $25.89 \%$; diseases of the nervous system - by $2.56 \%$; diseases of the circulatory system - by $3.64 \%$ [Tyumen Region Health Department, 2017].

Therefore, adequate technologies that improve the purification processes of natural waters, based on available materials and reagents, are important for the region. One such technology is the extraction of heavy metals of various natural and 
synthetic sorbents. This technology is compatible with the processes of reagent water treatment and is easily integrated into the existing technological scheme of water treatment plants in the city of Tyumen. Preliminary research on the use of adsorption materials as additional reagents at the Metelevo water supply facilities for the city of Tyumen have shown an increase in the operational efficiency of the station by an average of 35\% [Pimneva, Zagorskaya, 2014]. However, in order to select the most effective adsorption material, a more detailed study of the adsorption activity of all natural sorbents available in the region is needed.

\section{MATERIALS AND METHODS}

The purpose of this work was to study the adsorption activity of natural kaolinite and Kyshtyrlin montmorillonite clays as well as carbon sorbent with respect to heavy metal ions. The experiment was carried out at temperatures of 298 $\mathrm{K}$. The sorption of copper ions on sorbents was studied under static conditions from sulfate solutions with the concentrations of $0.05,0.1 ; 0.2$; $0.4 ; 0.6 ; 0.8 ; 1.0$ and $1.2 \mathrm{mmol} / \mathrm{ml}$. The sorbent in an amount of $1 \mathrm{~g}$ was poured into $50 \mathrm{ml}$ solutions. The contact of the sorbent with the solution was continued until equilibrium was established for 7 days. The sorbent and solution were then separated and analyzed for copper and zinc ions and the $\mathrm{pH}$ of the medium was measured. The concentration of cations in the solution was determined by complexometric titration with Trilon B in the presence of Murexide for copper.

On the basis of the obtained data, the static capacity of sorption of copper ions was obtained

$$
\mathrm{A}=\frac{\mathrm{C}_{0}-\mathrm{C}_{p}}{\mathrm{~g}} \cdot, \mathrm{mol} / \mathrm{g}
$$

and degree of sorption $\alpha(\%)$

$$
\alpha=\frac{\mathrm{C}_{0}-\mathrm{C}_{p}}{\mathrm{C}_{0}} \cdot 100 \%
$$

where $C_{0}$ - concentration of the element in the original solution, $\mathrm{mol} / \mathrm{l}$;

$C_{p}$ - equilibrium (residual) concentration of the extracted ion in solution, $\mathrm{mol} / \mathrm{l}$; $V$ - volume of solution, 1 ; $g$ - mass of sorbent, $g$.

Natural sorbents, i.e. kaolinitic and montmorillonite clays constitute a powder with particle sizes of 2-20 $\mu \mathrm{m}$. Figure 1 shows SEM-micrographs of the sorbent samples obtained on a scanning electron microscope. According to the data obtained, their main components are oxides in the quantities shown in the Table 1.

Losses on ignition of natural Kyshtyrlinsky montmorillonite clay are $8.66 \%$ and $2.22 \%$ of kaolinite clay. The atomic ratio of aluminum to silicon from the data presented is $\sim 1 / 2.6$ and this corresponds to the maximum number and strength of acidic centers of the surface of the aluminosilicate framework of kaolinite and montmorillonite clay. The active ions are $\mathrm{Na}^{+}$and $\mathrm{K}^{+}$ions, which participate in the exchange of heavy metal ions.
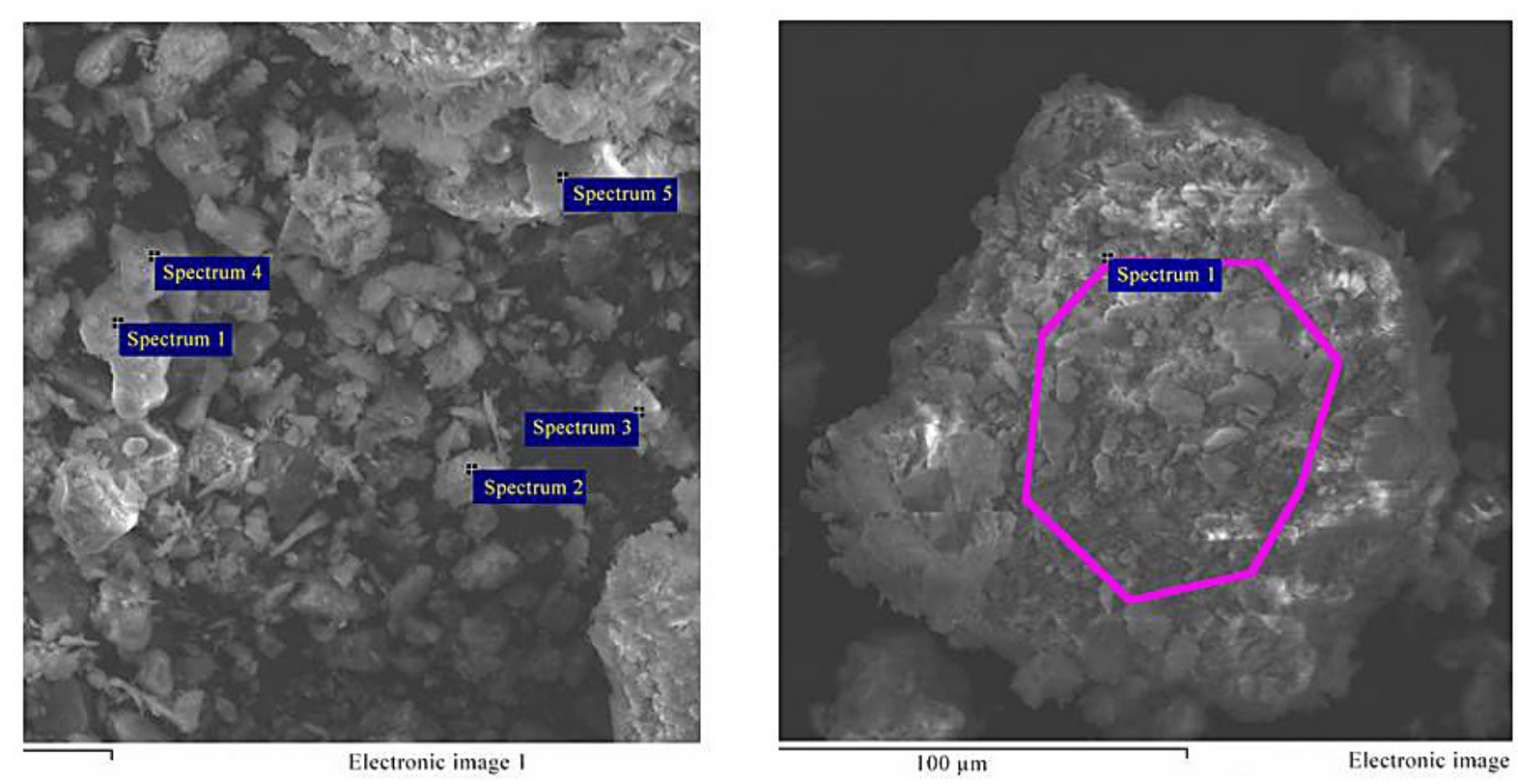

Figure 1. SEM-micrographs of kaolinite (a) and montmorillonite (b) clay 
Table 1. The chemical composition of montmorillonite and kaolinite clay

\begin{tabular}{|c|c|c|c|c|c|c|c|c|}
\hline Content & $\mathrm{SiO}_{2}$ & $\mathrm{Al}_{2} \mathrm{O}_{3}$ & $\mathrm{Na}_{2} \mathrm{O}$ & $\mathrm{K}_{2} \mathrm{O}$ & $\mathrm{CaO}$ & $\mathrm{Fe}_{2} \mathrm{O}_{3}$ & $\mathrm{TiO}_{2}$ & $\mathrm{MgO}$ \\
\hline $\mathrm{M}, \%$ mass & 54.0 & 20.73 & 0.75 & 3.07 & 0.44 & 9.43 & 1.1 & 1.82 \\
\hline $\mathrm{K}, \%$ mass & 54.55 & 27.23 & 1.29 & 0.96 & 3.81 & 9.94 & - & - \\
\hline
\end{tabular}

\section{RESULTS}

The investigated kaolinite and montmorillonite clays and carbon sorbent are microporous adsorbents possessing cation-exchange properties. According to the obtained experimental data, sorption of A ions of copper sulfate solutions on all investigated types of sorbents with different initial concentrations was calculated (Fig. 2).

With an increase in the concentration of copper ions in solution, the specific sorption on all three sorbents increases as well. As far as sorbability is concerned, sorbents can be arranged in the following order: kaolinite clay> montmorillonite clay $>$ carbon sorbent.

It can be seen from the graphical dependence (Figure 3) that with an increase in the initial concentration, the degree of purification of solutions from copper ions decreases monotonically on natural clays. On the carbonaceous sorbent, first, with increasing concentration, there is an increase in the extraction of copper ions and at a concentration of $0.012 \mathrm{mmol} / \mathrm{ml}$, a maximum is observed, and then begins to decrease. This can be explained by the fact that as the concentration of the initial solution increases, the ionic strength of the solutions increases as well, while the activity of copper ions decreases. Thus, free copper ions in the solution become smaller and the degree of sorption should decrease.

From a practical point of view, the efficiency of cleaning solutions depends on the ratio of sorbent consumption and the volume of the solution to be cleaned. It is known that the value of sorption $(\mathrm{A}, \mathrm{mmol} / \mathrm{g})$ is determined by the ratio of sorbent mass and ion content in the solution being purified, that is, its concentration and volume.

Figure 4 shows that with an increase in the ratio of the solid phase to the volume of the copper sulfate solution with a concentration of $0.02 \mathrm{M}$, an increase in the sorption value occurs. Hence, with a decrease in the S:L ratio, the content of copper ions in the solution ensures partial filling of active surface centers. The amount of absorbed ions naturally increases along with their content in the initial solution.

\section{CONCLUSION}

An analysis of the obtained results showed that natural kaolinite and montmorillonite clays, as well as carbon cationite, exhibit high sorption ability with respect to copper ions. The degree of sorption is influenced by the concentration of the copper solution. The use of natural

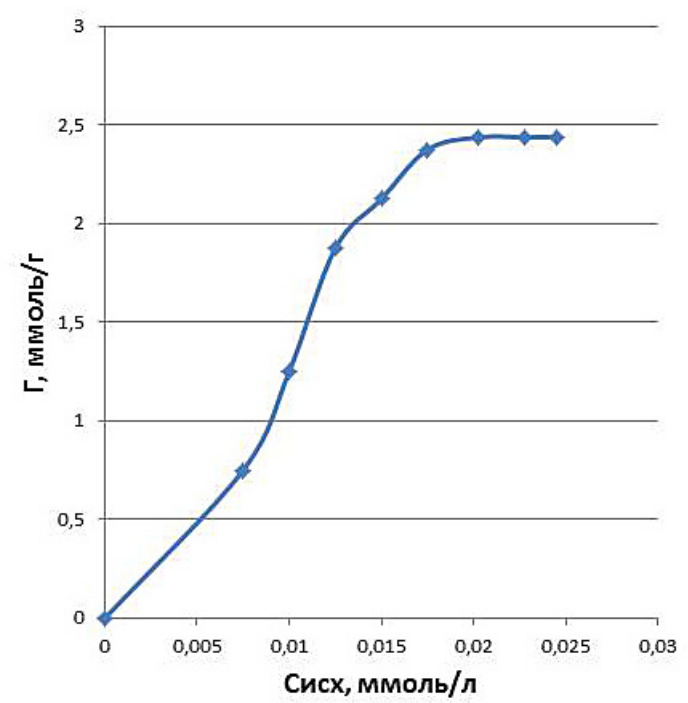

Figure 2. The dependence of copper ion adsorption on montmorillonite (1a), kaolinite clay (2a) and on carbon sorbent (b) 


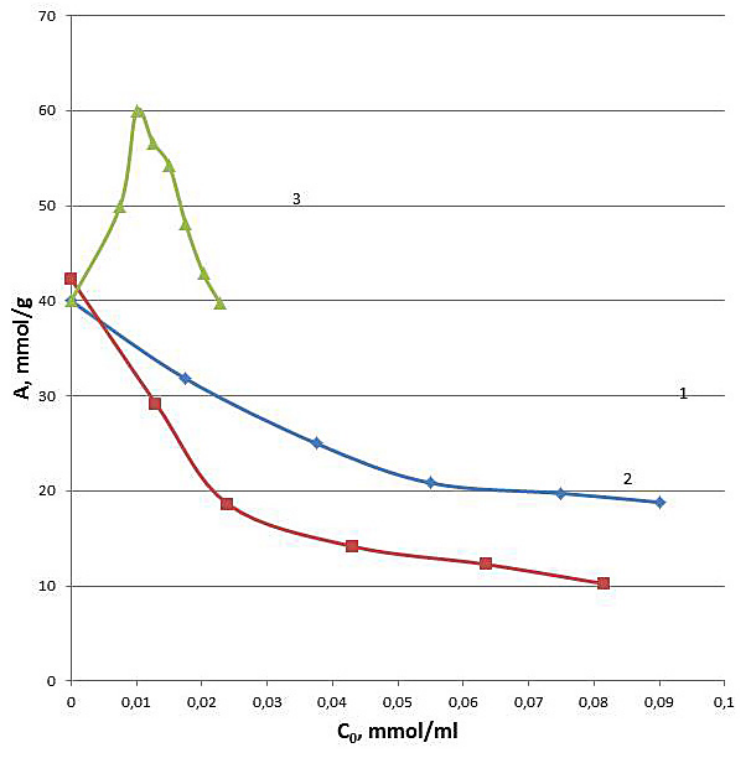

Figure 3. Dependence of sorption of copper ions from a solution with a concentration of $0.02 \mathrm{M}$ solution on the ratio of $\mathrm{S} / \mathrm{L}$ on kaolinite clay

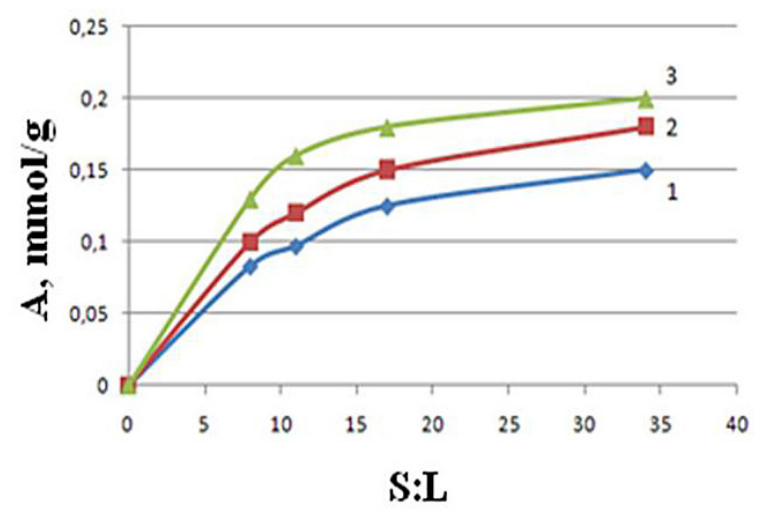

Figure 4. Dependence of sorption of copper ions from a solution with a concentration of $0.02 \mathrm{M}$ solution on the ratio of $\mathrm{S} / \mathrm{L}$ on kaolinite clay (1), montmorillonite clay (2), carbon cationite (3)

sorbents in dynamic conditions at natural waters treatment stations in the Tyumen region has a high potential, due to low cost, significant efficiency and ease of implementation in existing technological schemes.

Integration of dynamic adsorption into the composition of technological schemes of operat- ing water supply stations in the region will enable to intensify all stages of purification, reduce the consumption of the remaining reagents and improve the quality of drinking water, which will lead to an improvement in the quality of life in the region as a whole.

\section{REFERENCES}

1. Bykova E.A., Gashev S.N. 2014. Features of the accumulation of trace elements in the organism of small mammals in urbanization. Izvestiya of the Samara Scientific Center of the Russian Academy of Sciences. Vol. 16, 1(4), 1144-1148.

2. Gayevaya E.V., Zakharova E.V., Skipin L.N. 2013. Biogeochemistry of elements in the soil-plant-animal system in the south of the Tyumen region. Bulletin of the Krasnoyarsk State Agrarian University, $11,149-153$.

3. Guzeeva S.A. 2014. Ecological state of surface waters and bottom sediments of the city of Tyumen. Bulletin of the Krasnoyarsk State Agrarian University, 8, 134-139.

4. Pimneva LA, Zagorskaya A.A. 2014. Use of activated carbon to intensify the purification of natural waters of the Tyumen region. Modern problems of science and education, No. 6, 266.

5. Program for the comprehensive development of communal infrastructure systems of the Tyumen city. 2009. The decision of the Tyumen City Duma on June 25, 332.

6. Report on the environmental situation in the Tyumen region in 2015. 2016. Government of the Tyumen region.

7. Skipin L.N., Bersenyova A.G. 2014. Ecological assessment of urban areas on the example of the city of Tyumen. Agrarian Bulletin of the Urals, 2 (120), 71-73.

8. The report on the health of the population and the organization of health care in the Tyumen region based on the results of activities in 2016. 2017. RIC “Avex”, pp. 86.

9. Turnaeva E.A., Sidorenko O.V., Prikashchikova M.S., Turnova M.N. 2015. Change in the quality characteristics of water as a result of secondary pollution in the water networks of the city of Tyumen. Modern high technology, 12(1), 53-57. 